\title{
The Conditional Relation between Fama-French Betas
}

\section{and Return}

\author{
Stefan Koch and Christian Westheide ${ }^{\dagger}$
}

First version: January 15, 2008

This version: August 4, 2008

\begin{abstract}
According to asset pricing theory, in expectation there is a positive reward for taking risks. However, using realized returns, this relation is frequently reversed. In order to take this into account, we apply a conditional approach to the predominant model in asset pricing, the Fama-French three-factor model. We find that all three risk factors cross-sectionally drive asset returns. While other papers stop their analysis at this point, we derive a new test for the pricing of risks in multi-factor models within the conditional approach. Our test leads to qualitatively identical results as the widely used Fama-MacBeth test and hence confirms its validity.
\end{abstract}

Keywords: Empirical Asset Pricing, Beta Risk, Fama-French, Asymmetric Risk, Bootstrap

JEL-Classification: G12

\footnotetext{
${ }^{\dagger}$ Both authors are from Bonn Graduate School of Economics, University of Bonn. Stefan Koch: stkoch@uni-bonn.de, Christian Westheide: christian.westheide@uni-bonn.de. Both authors gratefully acknowledge financial support from German Science Foundation (DFG). We are thankful to Erik Theissen for invaluable discussions and to participants of CEF-QASS Conference on Empirical Finance, Warsaw International Economics Meeting, and Portuguese Finance Network Conference for their comments.
} 


\section{Introduction}

How does beta risk cross-sectionally affect asset returns? This question has inspired vast amounts of empirical research. Still, this issue has not been sufficiently answered. Several recent articles put the standard Fama and MacBeth (1973) test procedure into question and argue that a conditional approach as developed in Pettengill et al. (1995) is more appropriate. While many papers applying the conditional approach find a systematic conditional relationship between risk and return, most of this literature neglects to investigate if beta risk is a priced factor. This study considers the conditional cross-sectional risk-return relationship in a three-factor model and tests subsequently if beta risks based on the three factors are priced. Finally, this paper addresses the questions whether the market risk is not priced because an unsuitable estimation procedure is used or whether the irrelevance of market risk is an established fact.

The Capital Asset Pricing Model (CAPM), developed by Sharpe (1964), Lintner (1965) and Mossin (1966), is the first model which theoretically illustrates that market risk systematically affects returns. This model sets the foundation for modern asset pricing theory. Its central implication is that every asset's return is a linear function of its systematic risk, or market beta. Early research such as that of Black et al. (1972) and Fama and MacBeth (1973) empirically confirms the CAPM. In the following, several studies yield contradicting results. E.g., Reinganum (1981) and Lettau and Ludvigson (2001) find that a systematic relationship between market beta and average returns across assets does not exist.

On top of that, the so-called anomaly literature provides a vast amount of evidence in the 80's and 90's that the CAPM does not hold empirically. Banz (1981) documents that small firms have on average higher risk-adjusted returns than large firms in the US. This anomaly is entitled as the size effect. Moreover, Fama and French (1992) show that the estimated market beta and the average returns are not systematically related once the size and book-to-market factor are included. Finally, Fama and French (1993, 1996) argue that many of the CAPM anomalies are captured by the Fama-French three-factor model. Besides the inclusion of the market excess return as in the CAPM, the three-factor model considers the size and book-to-market factor. Since its inception the Fama-French three-factor model is the dominating model in empirical asset pricing.

However, Pettengill et al. (1995) propose a potential explanation of the observed weak relationship between market beta and stock returns. They point out that using realized returns implies that there exists a negative risk-return relationship in down-markets. 
Therefore, Pettengill et al. (1995) modify the Fama and MacBeth (1973) test procedure and develop a conditional approach incorporating the presumption that the risk-return relationship should be negative in down-markets. This is done by differentiating between periods with a positive risk premium (up-market) and a negative risk premium (down-market). As predicted by the conditional approach, the authors find a positive risk-return relationship in up-markets but an inverse relationship in down-markets for US data. Many other authors have followed their conditional test procedure. For instance, Fletcher (2000) also reports a positive significant relationship between market beta and returns in up-markets as well as a negative significant relationship in down-markets for international stocks. Elsas et al. (2003) confirm the results for Germany and Hung et al. (2004) for the UK as well as Huang and Hueng (2007) for daily instead of monthly US data.

However, the standard Fama-MacBeth procedure and the conditional approach test different hypotheses. Although either verifies if there exists a systematic relationship between risk and return, the Fama-MacBeth procedure additionally tests if investors receive a positive reward for holding risk, i.e. it tests if the risk premium is positive. According to Pettengill et al. (1995) this is the case if the following two conditions are satisfied: 1) the average market excess return is positive, 2) there is a symmetric relationship between the market risk premium in down- and in up-markets. Though, Freeman and Guermat (2006) disprove the validity of the second hypothesis and clarify that there should be a specific asymmetric relationship. Again, we want to emphasize in this context that the detection of a conditional relationship between beta and return does not mean that beta is a priced risk factor in asset returns and, thus, the model holds.

The goal of this paper is twofold. Firstly, we apply the conditional approach to the predominant model in empirical asset pricing, the Fama-French three-factor model, and test if the book-to-market beta and size beta retain their explanatory power once the conditional nature of the relation between betas and return is taken into account. Our empirical results yield strong support for the conditional approach. All three factors exhibit a strong positive risk-return relationship in up-markets as well as an inverse relationship in down-markets. While other studies do not find a relationship between market beta and return in the presence of the size and book-to-market factor, e.g. Fama and French (1992), this study detects a strong one.

Secondly, we do not only test if there is a systematic relationship between beta risk and return, but we also derive an adjusted procedure to test if beta risk is really a priced 
factor within the conditional approach. Our adjusted procedure automatically tests either hypotheses. Thus, it enables us to compare the standard Fama-MacBeth test with the conditional test procedure and to shed some light on previous studies dealing with the conditional approach. Our derivation of the adjusted conditional test extends the test of Freeman and Guermat (2006) to multifactor models. Within the framework of the CAPM Freeman and Guermat show that the adjusted conditional test has a power similar to that of the the standard Fama-MacBeth test under the assumption of normally distributed returns. However, they conjecture that the conditional test is more powerful when applied to empirical data because of the unconditional leptokurtosis in observed stock returns. In order to evaluate their conjecture, we use empirical stock market data rather than simulations. Furthermore, in constrast to most of the existing literature on the conditional relationship between risk factors and returns, we allow for time-variant betas. Our results illustrate that the market beta is not a priced factor, whereas the size and book-to-market beta are priced. Those results are qualitatively identical to those from the standard Fama-MacBeth test and hence, our study supports the results in Freeman and Guermat (2006). Contrariwise, our results conflict with other studies, e.g. Pettengill et al. (1995), basing their test on the above mentioned hypothesis that there is a symmetric relationship between the expected market excess return in down- and in up-markets. ${ }^{1}$ The remainder of the paper is organized as follows. In the next section we introduce the conditional approach in the setting of the Fama-French three-factor model and the econometric methodology. Section 3 discusses the data and the construction of the size and book-to-market factor. Section 4 reports the empirical results of the standard FamaMacBeth and the conditional test. Subsequently, we present the derivation of the adjusted conditional test as well as its empirical results. Section 6 concludes.

\section{Methodology}

We consider the Fama-French three-factor model and, in contrast to most of the existing literature, allow for time-varying betas. The decision to allow the sensitivities to the risk factors to change over time is made in view of the several decades long data set used and the apparent change in asset and portfolio betas over time that is found in the data. The relevance of time-varying betas is emphasized in several papers, e.g. Harvey (1989), Ferson and Harvey $(1991,1993)$ as well as Jagannathan and Wang (1996). The three risk

\footnotetext{
${ }^{1}$ We wish to emphasize that we do not remove all problems associated with empirical tests of asset pricing models like e.g. the unobservability of the market portfolio as mentioned by Roll (1977).
} 
factors of the Fama-French model are denoted by $m$ for market risk, $s m b$ for the size risk factor ('small minus big') relating to the market value of equity, and $h m l$ for the bookto-market factor ('high minus low'). Thus, the sensitivities of a portfolio $i$ to the risk factors at time $t$ are denoted $\beta_{i, t}^{m}, \beta_{i, t}^{s m b}, \beta_{i, t}^{h m l}$. Our empirical validations are based on the Fama-MacBeth (1973) approach, which is widely used in empirical asset pricing. Besides the advantage of an easy implementation it automatically corrects standard deviations for heteroscedasticity, which is a widespread problem among asset returns. We estimate the Fama-French betas for every portfolio from the following time-series regression,

$$
r_{i, t}^{e}=\alpha_{i, t}+\beta_{i, t}^{m} r_{m, t}^{e}+\beta_{i, t}^{s m b} r_{s m b, t}+\beta_{i, t}^{h m l} r_{h m l, t}+\epsilon_{i, t}
$$

where $r_{i, t}^{e}$ denotes the excess return of asset $i, r_{m, t}^{e}$ its market excess return, $r_{s m b, t}$ and $r_{h m l, t}$ its returns on the smb and hml portfolios, respectively. This procedure is repeated by rolling the window of 60 months of observations one month ahead. Rolling windows of five years make an appropriate compromise between adjusting to the latest changes and avoiding of noise in the monthly estimations. The rolling five year windows have also been suggested in earlier literature such as Groenewold and Fraser (1997) and Fraser et al. (2004). The next step consists in estimating the risk premia $\lambda_{0, t}, \lambda_{m, t}, \lambda_{s m b, t}$ and $\lambda_{h m l, t}$ using the estimated betas $\hat{\beta}_{i, t}^{m}, \hat{\beta}_{i, t}^{s m b}$ and $\hat{\beta}_{i, t}^{h m l}$ from equation 1 , i.e. computing cross-sectional regressions for every month,

$$
r_{i, t}^{e}=\lambda_{0, t}+\lambda_{m, t} \hat{\beta}_{i, t}^{m}+\lambda_{s m b, t} \hat{\beta}_{i, t}^{s m b}+\lambda_{h m l, t} \hat{\beta}_{i, t}^{h m l}+\eta_{i, t}
$$

The $\lambda_{j, t}$ 's, $j=0, m, s m b, h m l$, are the risk premia which offset the investors for the risk taken. The coefficient $\lambda_{0, t}$ is interpreted as the expected return of a zero beta portfolio, $\lambda_{m, t}$ as the market price of risk, $\lambda_{s m b, t}$ and $\lambda_{h m l, t}$ as the price of risk stemming from the size and the book-to-market value of the firm. ${ }^{2}$ Since the betas are estimated from a first-step regression, standard errors for the second regression can be misleading. In order to circumvent the presence of this errors-in-variables problem we apply a correction to the standard errors as proposed by Shanken (1992). Even though, the Shanken correction has to be treated critically because in practical applications it often yields a modified cross-product of the estimated beta vectors that is not positive definite as it should be. ${ }^{3}$

\footnotetext{
${ }^{2}$ The interpretation of the size and book-to-market risk is discussed in the literature. For instance, according to Amihud and Mendelson (1986, 1991) size may proxy for liquidity risk and Vassalou and Xing (2004) argue that the book-to-market ratio captures default risk.

${ }^{3}$ See Shanken and Weinstein (2006).
} 
Estimating equation 2 by the Fama-MacBeth procedure leads to conclusions on whether the risk factors are priced. For instance, if $\lambda_{m, t}$ is nonzero, market risk is a priced factor. If, on the other hand, $\lambda_{m, t}$ is not distinguishable from zero, then market risk is not priced. This can be the case either if there does not exist a relationship between beta and return or if it does exist but the market risk premium is not distinguishable from zero. Therefore, it is possible that beta is not priced despite the existence of a risk-return relationship. On this account we apply a procedure suggested by Pettengill et al. (1995), which exclusively tests the relationship between beta and realized returns conditional on whether the market excess return, i.e. the realized market risk premium, is positive or negative. This test takes into account that empirical tests are based on realized returns although the CAPM is stated in expectational terms. According to the CAPM the expected risk premium is always positive ${ }^{4}$ and, thus, there should exist a positive risk-return relation. However, the realized risk premium can also be negative implying a negative relation between beta and return. In order to test the systematic relationship between risk and return the following equation is estimated:

$$
r_{i, t}^{e}=\lambda_{0, t}+\lambda_{m, t}^{+} \delta_{t} \hat{\beta}_{i, t}^{m}+\lambda_{m, t}^{-}\left(1-\delta_{t}\right) \hat{\beta}_{i, t}^{m}+\eta_{i, t}
$$

While Pettengill et al. conduct this procedure for the CAPM and for beta constant over time, we apply the Fama-French three-factor model and allow for time-varying betas. That is, we estimate the following equation.

$$
\begin{aligned}
r_{i, t}^{e} & =\lambda_{0, t}+\lambda_{m, t}^{+} \delta_{1, t} \hat{\beta}_{i, t}^{m}+\lambda_{m, t}^{-}\left(1-\delta_{1, t}\right) \hat{\beta}_{i, t}^{m} \\
& +\lambda_{s m b, t}^{+} \delta_{2, t} \hat{\beta}_{i, t}^{s m b}+\lambda_{s m b, t}^{-}\left(1-\delta_{2, t}\right) \hat{\beta}_{i, t}^{s m b}+\lambda_{h m l, t}^{+} \delta_{3, t} \hat{\beta}_{i, t}^{h m l}+\lambda_{h m l, t}^{-}\left(1-\delta_{3, t}\right) \hat{\beta}_{i, t}^{h m l}+\eta_{i, t}
\end{aligned}
$$

The $\delta$ 's are dummy variables with the value 1 if the market, the $s m b$ and the $h m l$ portfolios, respectively, yield a positive excess return and 0 otherwise. This means we conduct separate regressions for up- and down-periods of the three risk factors for every month. Afterwards, the parameters are averaged to obtain estimates for the risk premia.

While the Fama-MacBeth procedure tests whether betas are priced risk factors, the conditional approach as applied here only enables us to test whether there is a systematic relation between a risk factor and the realized returns. In other words, finding a significant relation between beta risk and return does not automatically imply that beta risk is priced and the model holds.

\footnotetext{
${ }^{4}$ This follows from the assumption that agents are risk averse and that there is a positive net supply of market risk.
} 


\section{Data}

This study bases upon monthly data from July 1926 through December $2006^{5}$. Our dataset consists of 25 portfolios formed according to the same criteria as those used in Fama and French $(1992,1993)$. These data are value-weighted for the intersections of five size and five book-to-market equity portfolios. The portfolios are constructed at the end of June, and size is measured by market capitalization of equity at the end of June. The book-to-market ratio is book equity at the last fiscal year end of the prior calendar year divided by the market capitalization at the end of December of the prior year. Furthermore, this study employs the three Fama-French factors. Although the composition of the market portfolio is not observable, we approximate the market excess return by the value-weighted return on all NYSE, AMEX and NASDAQ stocks (from CRSP) minus the one-month Treasury bill-rate (from Ibbotson Associate). The size and book-to-market factor base on six portfolios, which are the intersections of two portfolios formed on size and three portfolios formed on book-to-market. Portfolios consisting of small (big) firms are denominated as small (big) portfolios, wheras portfolios consisting of firms with a low (high) book-to-market value are denoted as growth (value) portfolios. The size factor (smb) is constructed as the difference between the average return on three small portfolios and the average return on three big portfolios. The book-to-market factor $(\mathrm{hml})$ is the average return on the two value portfolios minus the average return on the two growth portfolios. The returns are based on all NYSE, AMEX and NASDAQ stocks, for which book and market equity data are available.

\section{Results}

\subsection{Fama-MacBeth regressions}

Before presenting the results of the unconditional test resulting from conducting the FamaMacBeth procedure, we want to stress the importance of taking time-variant betas. Figures 1,2, and 3 illustrate the variation in time of the market beta, the size beta as well as the book-to-market beta. Exemplarily, portfolios 1, 10 and 25 are taken. Portfolio 1 contains the smallest growth stocks, portfolio 10 stocks with only slightly larger market capitalization and high book-to-market ratio, and portfolio 25 consists of the biggest value stocks. In particular, portfolios 1 and 25 indicate a strong variation in the betas

\footnotetext{
${ }^{5}$ Data are taken from Kenneth French's homepage.
} 
Table 1: Fama-MacBeth test (1931:07-2006:12)

\begin{tabular}{|c|c|c|c|c|}
\hline Variable & $\lambda$ & t-stat & t-stat + & $\mathrm{R}^{2}$ \\
\hline cons & 0.86 & $4.60^{* * *}$ & $4.55^{* * *}$ & 0.79 \\
market & -0.15 & -0.61 & -0.61 & \\
$\mathrm{smb}$ & 0.21 & $1.83^{*}$ & $1.81^{*}$ & \\
$\mathrm{hml}$ & 0.45 & $3.56^{* * *}$ & $3.53^{* * *}$ & \\
& $*$ significant (10-percent level) \\
$* * *$ significant (1-percent level)
\end{tabular}

This table depicts the results for the Fama-French three-factor model illustrated by equation 2. cons denotes the constant term, market the risk premium of the market risk, smb that of the size and hml that of the book-to-market risk. The coefficients are given as percentage points per month. The t-stat ${ }^{+}$ represents the t-values based on standard deviations adjusted by the Shanken correction.

across time. Although the betas in figure 2 appear to be much less variable, even in this case market beta varies between 0.62 and 1.25, size beta between 0.69 and 1.22 and book-to-market beta between 0.50 and 1.23.

Table 1 shows the results of the Fama-MacBeth estimation for the whole period. The monthly estimates of the coefficients are averaged and a $t$-test is applied to determine the statistical significance of the mean of the estimated coefficients. The market beta is negative but insignificant and, thus, market risk is not found to be priced. Size risk is found to be significant at the 10 percent level while that of the book-to-market factor is highly significant. The constant representing the return of the zero-beta portfolio should be between the average riskless borrowing and lending rate. The estimated value is implausibly high for the average investor. However, this is a feature occurring in most empirical studies. In the following we conduct the same analysis for four subperiods, the results being detailed in table 2 . The subperiods are chosen such that they are of almost equal length. We observe that the size beta is not significant in any of the subperiods whilst the market risk surprisingly yields a significantly negative risk premium in the last period. The significance of the book-to-market risk varies, though, it is priced at the 10 percent in all periods except in the first one, while its coefficient, as that of the size factor, has the expected sign in all subperiods. Generally, though rarely done so in the literature, applying the Shanken (1992) correction to the standard errors would be advisable in order to overcome the errors-in-variables problem. However, as tables 1 and 2 show, the correction factors are negligible so that we can disregard the correction in the following. 
Figure 1: Fama-French Betas for portfolio 1 (1931:07-2006:12)

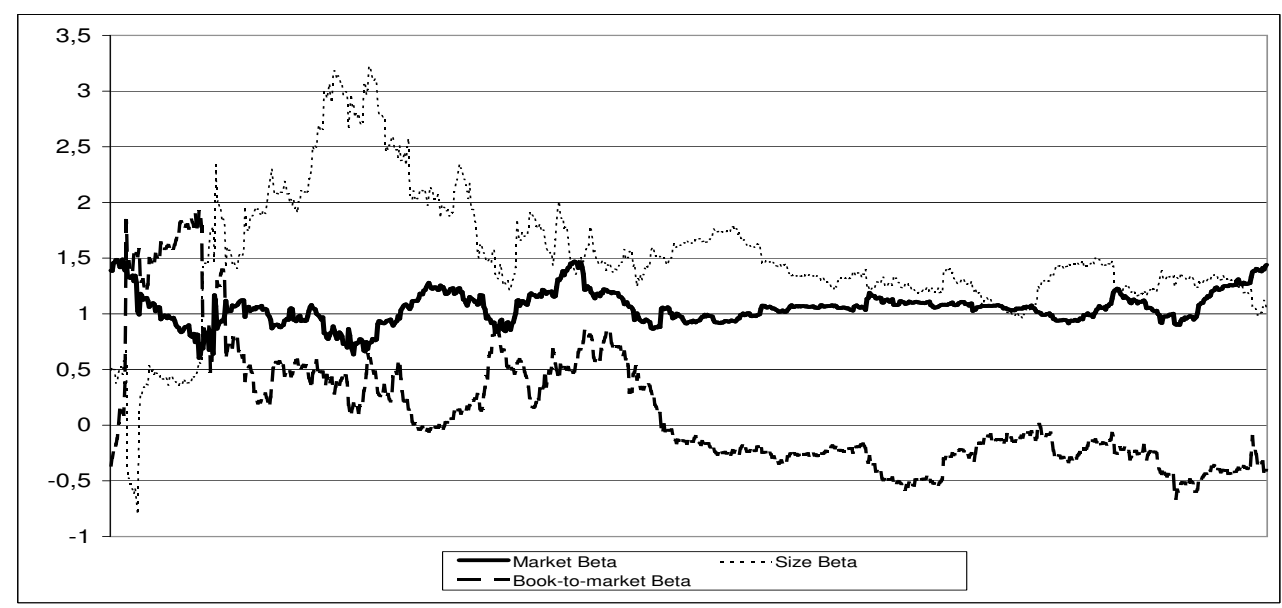

Figure 2: Fama-French Betas for portfolio 10 (1931:07-2006:12)

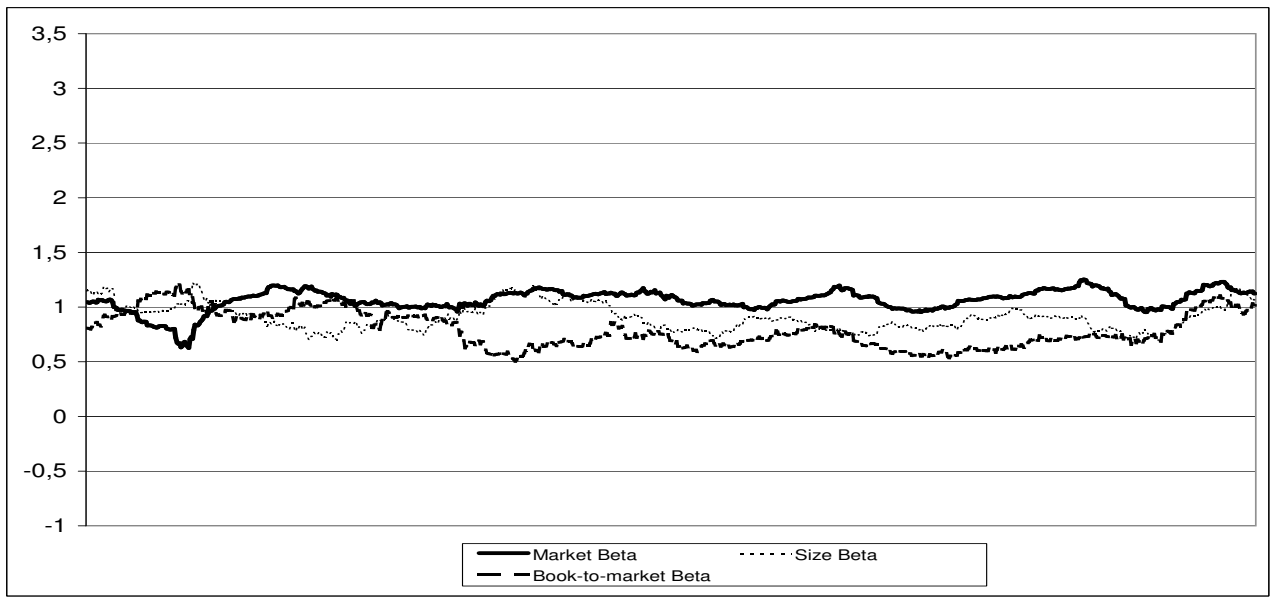

Figure 3: Fama-French Betas for portfolio 25 (1931:07-2006:12)

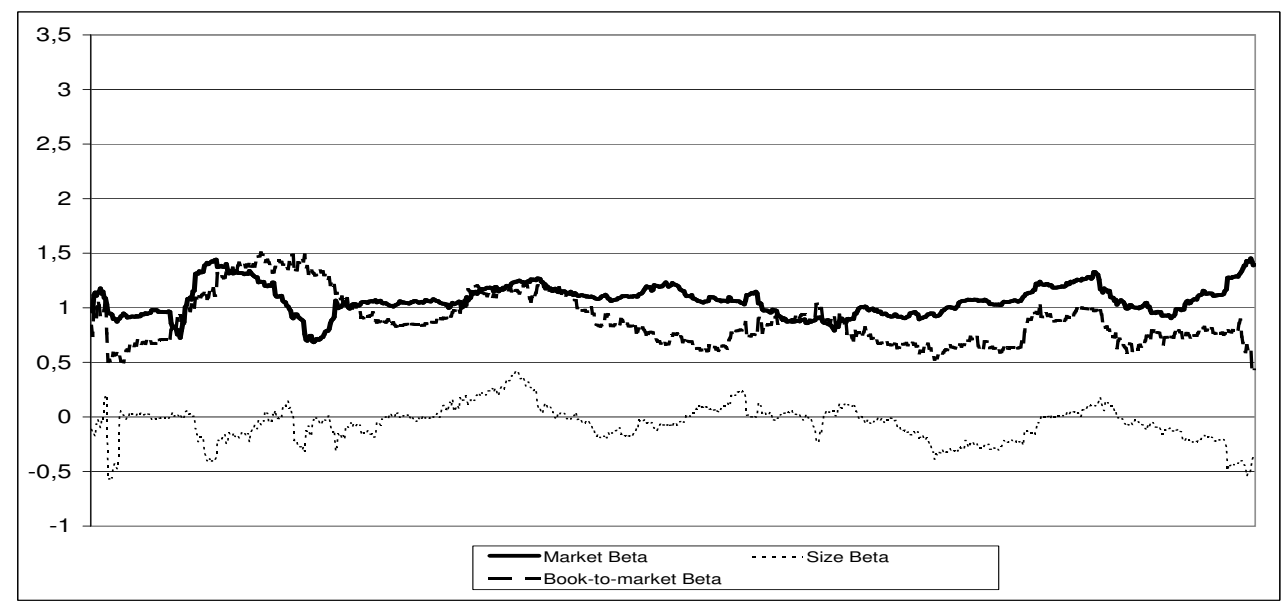


Table 2: Fama-MacBeth test (subperiods)

\begin{tabular}{|c|c|c|c|c|c|c|c|c|}
\hline \multirow[b]{2}{*}{ Variable } & \multicolumn{4}{|c|}{ 1931:07-1949:12 } & \multicolumn{4}{|c|}{ 1950:01:1968:12 } \\
\hline & $\lambda$ & t-stat & t-stat ${ }^{+}$ & $\mathrm{R}^{2}$ & $\lambda$ & t-stat & t-stat ${ }^{+}$ & $\mathrm{R}^{2}$ \\
\hline cons & -0.15 & -0.28 & -0.28 & 0.93 & 1.24 & $4.82^{* * *}$ & $4.73^{* * *}$ & 0.68 \\
\hline market & 1.06 & 1.45 & 1.43 & & -0.26 & -0.77 & -0.76 & \\
\hline $\mathrm{smb}$ & 0.47 & 1.48 & 1.46 & & 0.22 & 1.46 & 1.43 & \\
\hline $\mathrm{hml}$ & 0.58 & 1.48 & 1.46 & & 0.30 & $2.09^{* *}$ & $2.05^{* *}$ & \\
\hline \multirow[b]{2}{*}{ Variable } & \multicolumn{4}{|c|}{ 1969:01-1987:12 } & \multicolumn{4}{|c|}{ 1988:01-2006:12 } \\
\hline & $\lambda$ & t-stat & t-stat ${ }^{+}$ & $\mathrm{R}^{2}$ & $\lambda$ & t-stat & t-stat ${ }^{+}$ & $\mathrm{R}^{2}$ \\
\hline cons & 0.66 & $2.17^{* *}$ & $2.14^{* *}$ & 0.79 & 1.65 & $5.23^{* * *}$ & $5.06^{* * *}$ & 0.78 \\
\hline market & -0.40 & -0.95 & -0.93 & & -0.99 & $-2.32^{* *}$ & $-2.25^{* *}$ & \\
\hline smb & 0.05 & 0.28 & 0.27 & & 0.12 & 0.49 & 0.48 & \\
\hline $\mathrm{hml}$ & 0.53 & $2.76^{* * *}$ & $2.71^{* * *}$ & & 0.39 & $1.79^{*}$ & $1.73^{*}$ & \\
\hline
\end{tabular}

\footnotetext{
* significant (10-percent level)

** significant (5-percent level)

*** significant (1-percent level)
}

This table depicts the results for the Fama-French three-factor model for four subperiods. cons denotes the constant term, market the risk premium of the market risk, smb that of the size and hml that of the book-to-market risk. The coefficients are given as percentage points per month. The t-stat ${ }^{+}$represents the t-values based on standard deviations adjusted by the Shanken correction.

Additionally, we calculated a cross-sectional $R^{2}$. Although it is not a formal test of model specification, it is an informative criterion of the goodness of fit. ${ }^{6}$ The Fama-French Model explains $79 \%$ of the cross-sectional variation in stock returns, which is in line with previous studies, e.g. Lettau and Ludvigson (2001).

\subsection{Conditional Relationship}

First of all we check how frequently the realized excess return is negative. If it were seldom negative, the conditional relationship would have an ineffectual impact on tests of the relationship between beta and return. The riskfree rate exceeds the market return in $40 \%$ of the observations for the entire period. Moreover, in $48 \%$ of the observations the size factor and in $43 \%$ the book-to-market factor is negative, which accentuates the relevance of the distinction between up-markets and down-markets. Testing for the conditional relationship between Fama-French betas and returns shows highly significant results for

\footnotetext{
${ }^{6}$ The cross-sectional $R^{2}$ is calculated as follows: $\left[\operatorname{Var}\left(\bar{r}_{i}\right)-\operatorname{Var}\left(\bar{\eta}_{i}\right)\right] / \operatorname{Var}\left(\bar{r}_{i}\right)$.
} 
Table 3: Conditional Relation between Fama-French Betas and Returns (1931:06-2006:12)

\begin{tabular}{|c|c|c|}
\hline Variable & $\lambda$ & t-stat \\
\hline cons & 0.86 & $4.60^{* * *}$ \\
market-up & 2.62 & $8.57^{* * *}$ \\
market-down & -4.34 & $-13.64^{* * *}$ \\
smb-up & 2.27 & $14.33^{* * *}$ \\
smb-down & -2.00 & $-22.47^{* * *}$ \\
hml-up & 2.38 & $15.19^{* * *}$ \\
hml-down & -2.09 & $-18.01^{* * *}$ \\
*** significant (1-percent level)
\end{tabular}

This table depicts the results of the conditional relation between Fama-French betas and return illustrated in equation 4 for the entire sample. cons denotes the constant term, market up (down) the risk premium of the market given that the excess market return is positive (negative), smb up (down) that of the size given that the smb factor is positive (negative)and hml up (down) that of the book-to-market risk given that the $\mathrm{hml}$ factor is positive (negative). The coefficients are given as percentage points per month.

all three risk factors as depicted in tables 3 and 4 . The fact that we observe a strong relationship between market risk and returns is among others consistent with Pettengill et al. (1995) and Fletcher (2000). Moreover, our results clarify that there also exists a strong conditional relationship between returns and size as well as book-to-market beta. Market beta is associated with increasing absolute returns, i.e. positively increasing returns in up- and negatively increasing returns in down-markets. The same applies to the size and book-to-market risk factors while the constant, as expected, does not change compared with the results of the Fama-MacBeth method. In contrast to Pettengill et al. (1995) the coefficients show asymmetry concerning the market risk. The returns increase less with beta when the market excess return is positive than they decrease when it is negative. This might intuitively explain why, while the market on average increases and beta relates asset returns to market returns, there is no significant risk premium for the market risk. In contrast, the coefficients for the size and book-to-market risk are not significantly asymmetric. ${ }^{7}$ The tests for the subperiods show comparable results and how the asymmetry concerning the market risk varies significantly over time. In contrast to the findings of the standard Fama-MacBeth procedure the conditional approach leads to results that are consistent over time. All variables retain significance when we focus on one of the four subperiods.

\footnotetext{
${ }^{7}$ Testing for asymmetric coefficients results in the following test values: $-3.9^{* * *}$ (market), 1.49 (smb) and $1.49(\mathrm{hml})$. The null hypothesis is $\lambda_{j}^{+}+\lambda_{j}^{-}=0$.
} 
Table 4: Subperiods

\begin{tabular}{|l|cl|cl|cl|cc|}
\hline & \multicolumn{2}{|c|}{$1931: 07-1949: 12$} & \multicolumn{2}{|c|}{$1950: 01: 1968: 12$} & \multicolumn{2}{c|}{$1969: 01-1987: 12$} & \multicolumn{2}{c|}{$1988: 01-2006: 12$} \\
Variable & $\lambda$ & t-stat & $\lambda$ & t-stat & $\lambda$ & t-stat & $\lambda$ & t-stat \\
\hline cons & -0.15 & -0.28 & 1.24 & $4.73^{* * *}$ & 0.66 & $2.14^{* *}$ & 1.65 & $5.06^{* * *}$ \\
market-up & 4.30 & $4.52^{* * *}$ & 1.62 & $4.45^{* * *}$ & 3.08 & $5.93^{* * *}$ & 1.72 & $3.76^{* * *}$ \\
market-down & -3.78 & $-4.02^{* * *}$ & -3.87 & $-8.65^{* * *}$ & -4.20 & $-9.05^{* * *}$ & -5.54 & $-9.98^{* * *}$ \\
smb-up & 2.60 & $5.44^{* * *}$ & 1.69 & $9.98^{* * *}$ & 2.19 & $10.57^{* * *}$ & 2.59 & $9.13^{* * *}$ \\
smb-down & -2.17 & $-11.70^{* * *}$ & -1.39 & $-10.60^{* * *}$ & -2.12 & $-12.36^{* * *}$ & -2.31 & $-11.53^{* * *}$ \\
hml-up & 3.53 & $6.07^{* * *}$ & 1.55 & $9.01^{* * *}$ & 2.21 & $13.85^{* * *}$ & 2.38 & $10.94^{* * *}$ \\
hml-down & -2.59 & $-9.00^{* * *}$ & -1.30 & $-10.40^{* * *}$ & -2.20 & $-10.41^{* * *}$ & -2.24 & $-9.57^{* * *}$ \\
\hline
\end{tabular}

\footnotetext{
*** significant (1-percent level)

** significant (5-percent level)
}

This table depicts the results of the conditional relation between Fama-French betas and return illustrated in equation 4 for the four subperiods. cons denotes the constant term, market up (down) the risk premium of the market given that the excess market return is positive (negative), smb up (down) that of the size given that the smb factor is positive (negative)and hml up (down) that of the book-to-market risk given that the hml factor is positive (negative). The coefficients are given as percentage points per month.

We do not report the $R^{2}$ since they comply with the values of the Fama-MacBeth procedure. $^{8}$

\section{$5 \quad$ Testing for Priced Betas}

\subsection{Derivation of the Test}

Our findings in the last section exclusively provide strong evidence for a systematic relationship between Fama-French betas and return. In this section we go one step further and test not only if there exists a systematic relationship between beta and return but also if beta risk is priced within the conditional approach. Besides the existence of a systematic relationship a priced beta would require a reward to compensate investors for the risk taken. In the following we derive an adjusted test based on the conditional approach, which tests if the Fama-French betas are priced. Since the adjusted test and the standard Fama-MacBeth procedure are now based on the same hypothesis, it enables us to compare

\footnotetext{
${ }^{8}$ The conditional approach is based on the same regressions as the Fama-MacBeth test but it splits up the variables in up-markets and down-markets. Therefore, the constant and the cross-sectional $R^{2}$ are identical.
} 
both procedures and to judge the relevance of the conditional approach. Resting their test on the CAPM, our adjusted test extends the test of Freeman and Guermat (2006) to more general models. Moreover, we allow for time-variant betas. Consider the following return generating process:

$r_{i, t}^{e}=E\left(r_{i, t}^{e}\right)+\beta_{i, t}^{m}\left[r_{m, t}^{e}-E\left(r_{m, t}^{e}\right)\right]+\beta_{i, t}^{s m b}\left[r_{s m b, t}-E\left(r_{s m b, t}\right)\right]+\beta_{i, t}^{h m l}\left[r_{h m l, t}-E\left(r_{h m l, t}\right)\right]+\epsilon_{i, t}$

The error term $\epsilon_{i, t}, E\left[\epsilon_{i, t}\right]=0$, is assumed to be uncorrelated with both the betas and the excess returns. Even though, it can be cross-sectionally correlated. Additionally, consider the expected return process:

$$
E\left(r_{i, t}^{e}\right)=\alpha_{i, t}+\beta_{i, t}^{m} \pi_{t}^{m}+\beta_{i, t}^{s m b} \pi_{t}^{s m b}+\beta_{i, t}^{h m l} \pi_{t}^{h m l}
$$

$\alpha_{i, t}$ represents a compensation for other risk factors that are orthogonal to the three included factors. Hence, it is assumed that $\alpha_{i, t}$ and $\beta_{i, t}$ are uncorrelated. Choosing $\alpha_{i, t}=0, \pi_{t}^{m}=E\left[r_{m, t}^{e}\right], \pi_{t}^{s m b}=E\left[r_{s m b, t}\right]$ and $\pi_{t}^{h m l}=E\left[r_{h m l, t}\right]$ would imply that the return process equals the Fama-French three-factor model. To put it differently, if $\pi_{t}^{j}=0$, the risk factor $j$ is not priced. This approach enables us to verify if beta risk is priced. For instance, testing the sole hypothesis that market risk is not priced under the assumption of a three-factor model, corresponds to the null hypothesis $\pi_{t}^{m}=0$, whereas the other two factors are still contained in the model i.e. $\pi_{t}^{s m b}=E\left[r_{s m b, t}\right]$ and $\pi_{t}^{h m l}=E\left[r_{h m l, t}\right] .{ }^{9}$

Exemplarily, the following test is derived under the null hypothesis that market beta is unpriced. This test can be equivalently derived for the other two factors and the resulting equation will be analogous. We begin with the linear regression equation of our model.

$$
r_{i, t}^{e}=\lambda_{0, t}+\lambda_{m, t} \beta_{i, t}^{m}+\lambda_{s m b, t} \beta_{i, t}^{s m b}+\lambda_{h m l, t} \beta_{i, t}^{h m l}
$$

According to the Fama-MacBeth procedure ordinary least squares regressions are conducted for all $\mathrm{t}$

$$
\begin{aligned}
\lambda_{m, t} & =\operatorname{cov}\left(\beta_{i, t}^{m}, r_{i t}^{e}\right) \operatorname{var}\left(\beta_{i, t}^{m}\right)^{-1} \\
& =\operatorname{cov}\left(\beta_{i, t}^{m}, E\left[r_{i, t}^{e}\right]\right) \operatorname{var}\left(\beta_{i, t}^{m}\right)^{-1}+r_{m, t}^{e}-E\left[r_{m, t}^{e}\right]+\kappa_{t}^{m, s m b}\left(r_{s m b, t}-E\left[r_{s m b, t}\right]\right) \\
& +\kappa_{t}^{m, h m l}\left(r_{h m l, t}-E\left[r_{h m l, t}\right]\right) \\
& =\mathrm{r}_{m, t}^{e}-E\left[r_{m, t}^{e}\right]+\pi_{t}^{m}+\kappa_{t}^{m, s m b}\left(r_{s m b, t}-E\left[r_{s m b, t}\right]+\pi_{t}^{s m b}\right)+\kappa_{t}^{m, h m l}\left(r_{h m l, t}-E\left[r_{h m l, t}\right]+\pi_{t}^{h m l}\right),
\end{aligned}
$$

\footnotetext{
${ }^{9}$ Setting $\pi_{t}^{s m b}=E\left[r_{s m b, t}\right]$ and $\pi_{t}^{h m l}=E\left[r_{h m l, t}\right]$ does not make any statement about the significance of these two factors.
} 
where $\kappa_{t}^{m, s m b}=\operatorname{cov}\left(\beta_{i, t}^{m}, \beta_{i, t}^{s m b}\right) \operatorname{var}\left(\beta_{i, t}^{m}\right)^{-1}$ and $\kappa_{t}^{m, h m l}=\operatorname{cov}\left(\beta_{i, t}^{m}, \beta_{i, t}^{h m l}\right) \operatorname{var}\left(\beta_{i, t}^{m}\right)^{-1}$. Under the null hypothesis we obtain:

$$
\begin{aligned}
\lambda_{m}^{+} & =\mathrm{E}\left[\mathrm{r}_{m, t}^{e} \mid r_{m, t}^{e}>0\right]-E\left[r_{m, t}^{e}\right]+E\left[\kappa_{t}^{m, s m b} r_{s m b, t} \mid r_{m, t}^{e}>0\right]+E\left[\kappa_{t}^{m, h m l} r_{h m l, t} \mid r_{m, t}^{e}>0\right] \\
\lambda_{m}^{-} & =\mathrm{E}\left[\mathrm{r}_{m, t}^{e} \mid r_{m, t}^{e}<0\right]-E\left[r_{m, t}^{e}\right]+E\left[\kappa_{t}^{m, s m b} r_{s m b, t} \mid r_{m, t}^{e}<0\right]+E\left[\kappa_{t}^{m, h m l} r_{h m l, t} \mid r_{m, t}^{e}<0\right] \\
\lambda_{m}^{+}+\lambda_{m}^{-} & =\mathrm{E}\left[\mathrm{r}_{m, t}^{e} \mid r_{m, t}^{e}>0\right]+E\left[r_{m, t}^{e} \mid r_{m, t}^{e}<0\right]-2 E\left[r_{m, t}^{e}\right]+E\left[\kappa_{t}^{m, s m b} r_{s m b, t} \mid r_{m, t}^{e}>0\right] \\
& +\mathrm{E}\left[\kappa_{t}^{m, s m b} r_{s m b, t}^{e} \mid r_{m, t}^{e}<0\right]+E\left[\kappa_{t}^{m, h m l} r_{h m l, t} \mid r_{m, t}^{e}>0\right]+E\left[\kappa_{t}^{m, h m l} r_{h m l, t} \mid r_{m t}^{e}<0\right]
\end{aligned}
$$

As the formula illustrates the relation between $\lambda_{m}^{+}$and $\lambda_{m}^{-}$is generally asymmetric under the null hypothesis and, hence, it stands in sharp contrast to Pettengill et al. (1995). They assume that priced beta risk corresponds to a symmetric relationship between $\lambda_{m}^{+}$and $\lambda_{m}^{-}$. However, there is no reasonable argument why the expected value of the risk premium conditional on it being positive or negative should have the same absolute expected size. Under the assumption of uncorrelated factors the correlation among the betas vanishes and hence, $\kappa_{t}^{m, s m b}=\kappa_{t}^{m, h m l}=0$. As a result the formula simplifies to the one-factor case and corresponds to the result in Freeman and Guermat (2006).

In order to avoid messy notation the right hand side of the last equation is denoted as $\theta_{m}$.

\subsection{The Bootstrap}

Since $\lambda_{j}^{+}+\lambda_{j}^{-}-\theta_{j}=0$ holds under the null hypothesis that risk factor $j, j \in\{m, s m b, h m l\}$, is not priced, this equation can be tested by a simple t-test:

$$
t=\frac{\hat{\lambda}_{j}^{+}+\hat{\lambda}_{j}^{-}-\hat{\theta}_{j}}{s \hat{t} d_{j}}
$$

$\theta$ can be consistenly estimated by taking sample averages. Provided that the standard deviation of the numerator $s t d_{j}$ can also be consistently estimated, the Central Limit Theorem can be applied and hence, the asymptotic normality of the statistic follows White (1999). However, since the components of $\theta$ are based on different sample sizes, the covariances cannot be estimated directly. One way to overcome this obstacle is to apply the bootstrap. The bootstrap was first proposed by Efron (1979). It helps us learn about the sample characteristics by taking resamples and using this information to infer to the population. As shown by Babu and Singh (1984) the bootstrap can be used to consistently estimate a wide range of statistics, including not only the sample mean but also the sample variance and smooth transforms of these statistics. In our setting the bootstrap is applied as follows. $T$ observations are independently drawn from the four variables 
$r_{j, t}^{e}, \lambda_{j}, r_{k, t} \kappa_{t}^{j, k}$ and $r_{l, t} \kappa_{t}^{j, l}$ with replacement where $k, l$ denote the two risk factors different from $j$. This gives us a new sample $\left(r_{j, t}^{e}{ }^{*}, \lambda_{j}^{*},\left(r_{k, t} \kappa_{t}^{j, k}\right)^{*},\left(r_{l, t} \kappa_{t}^{j, l}\right)^{*}\right)$. By calculating $\hat{\lambda}_{j}^{+*}$, $\hat{\lambda}_{j}^{-*}$ and $\hat{\theta}^{*}$ from the new sample, we obtain an estimate for the numerator. This result is saved and the whole procedure is repeated $\mathrm{S}$ times. Finally, the bootstrap variance is the sample variance of the $\mathrm{S}$ estimates of the numerator. In order to choose $\mathrm{S}$ sufficiently large, we take $\mathrm{S}$ equal to 10000.

However, this procedure relies on the assumption that returns are identically and independently distributed. In order to account for possible autocorrelation and clusterings we conduct the block bootstrap additionally. The Moving Block Bootstrap developed by Künsch (1989) draws blocks of length $l$ instead of drawing T observations independently.

Since the validity of the block bootstrap requires $\lim _{T \rightarrow \infty} \frac{l^{2}}{T}=0$, we choose $l=T^{\frac{1}{3}}$. Lahiri (1999) shows that the Moving block Bootstrap performs better than other block bootstraps in terms of the mean squared error. With repect to this criterion, Künsch (1989) determine that $l=T^{\frac{1}{3}}$ is the optimal order of the block length.

\subsection{Empirical Results}

This subsection presents the test results of the adjusted test developed in subsection 5.1 based on the simple bootstrap and the moving block bootstrap. Although $\theta_{j}$ is unknown and has to be estimated as well, we also consider the case of a known $\theta_{j}$ as a benchmark. By assuming a known $\theta_{j}$ the bootstrap becomes dispensable since the standard deviation can be solely calculated from the variances of $\hat{\lambda}_{j}^{+}$and $\hat{\lambda}_{j}^{-}$. Under this simplifying assumption Freeman and Guermat reinterpreted the results in Pettengill et al., Fletcher (2000) and Hung et al. (2004) by testing if the market beta is a priced risk factor within the conditional approach. In the case of Pettengill et al., which is the only study dealing with monthly US data, they draw the conclusion that market risk is a priced risk factor. Therefore, comparing the benchmark with the case of an unknown $\theta_{j}$ enables to shed some light on the results in Freeman and Guermat.

Table 5 illustrates the results of the adjusted test for the entire period. Under the assumption of known $\theta_{j}$ s the book-to-market and size coefficients are positive and highly significant, whereas the test value for market risk is negative but insignificant. Even though, those results must be handled with care since a constant $\theta_{j}$ leads to an underestimated standard deviation. This problem is reflected by the results from the simple bootstrap. The t-value dramatically decreases in absolute values for all parameters. For instance, size risk is only priced at a $10 \%$ level. Book-to-market is still priced at a $1 \%$ 
Table 5: Adjusted test (1931:07-2006:12)

\begin{tabular}{|c|c|c|c|c|}
\hline Variable & $\lambda_{j}^{+}+\lambda_{j}^{-}-\theta_{j}$ & t-stat $\left(\right.$ known $\left.\theta_{j}\right)$ & t-stat (simple Boots.) & t-stat (Block-Boots.) \\
\hline market & -0.45 & -1.01 & -0.81 & -0.85 \\
$\mathrm{smb}$ & 0.43 & $2.39^{* * *}$ & $1.85^{*}$ & $1.79^{*}$ \\
$\mathrm{hml}$ & 0.96 & $4.91^{* * *}$ & $3.88^{* * *}$ & $3.47^{* * *}$ \\
\hline \multicolumn{3}{|c}{} \\
\multicolumn{3}{|c}{} \\
\multirow{2}{*}{ * significant (10-percent level) } \\
*** significant (1-percent level)
\end{tabular}

This table depicts the results of the adjusted test for the entire period assuming a constant $\theta_{j}$ as well as applying the simple bootstrap and the block bootstrap, respectively. market is the risk premium of the market, smb that of the size and hml that of the book-to-market risk. $\lambda_{j}^{+}+\lambda_{j}^{-}-\theta_{j}$ are defined as presented in subsection 5.1.

level and market risk is not priced. In contrast to the findings in Freeman and Guermat our results show that the market beta is not a priced risk factor. The reason is twofold. Firstly, Freeman and Guermat use a constant $\theta_{m}$, which results in misleading t-values. The variance is underestimated and hence, the t-value is overestimated. Secondly, as already shown by Fama and French, the inclusion of size and book-to-market can distinctly decrease the explanatory power of the market factor and can cause insignficance of the coefficient. Thus, the results of the adjusted test are in line with previous tests.

Although the results from the block bootstrap are qualitatively identical in comparison to the simple bootstrap, the t-values change, e.g. the book-to-market and size coefficient exhibit a lower t-value, whereas the t-value for the market coefficient is slightly larger in absolute values. This indicates that the assumption of independently and identically distributed returns is not adequate in this context and the use of the block bootstrap is more appropriate. Therefore, the following results exclusively base on the block bootstrap.

Table 6 illustrates the results from the adjusted test for the four subperiods. Except for the second subperiod the coefficient for the market risk has a negative sign. Though, each of the coefficients is insignificant. In contrast to the standard Fama-MacBeth test the adjusted test does not exhibit that market risk is negatively priced in the fourth subperiod. Concerning the size risk all coefficients are positive but insignificant in each subperiod. The book-to-market risk factor is insignificant in the first period, significant at the $10 \%$ level in the second and fourth period and at the $1 \%$ level in the third period, which almost corresponds to the results from the standard Fama-MacBeth test. Moreover, both tests indicate large standard deviations and hence, smaller t-values for the subperiods, which leads to less significant and partly to inconsistent results. However, this phenomenon is 
Table 6: Adjusted test (Block Bootstrap)

\begin{tabular}{|l|cc|cc|}
\hline Variable & \multicolumn{2}{|c|}{$1931: 07-1949: 12$} & \multicolumn{2}{c|}{$1950: 01: 1968: 12$} \\
& $\lambda_{j}^{+}+\lambda_{j}^{-}-\theta_{j}$ & t-stat & $\lambda_{j}^{+}+\lambda_{j}^{-}-\theta_{j}$ & t-stat \\
\hline market & -1.24 & -0.85 & 0.62 & 0.93 \\
smb & 0.78 & 1.40 & 0.26 & 0.66 \\
$\mathrm{hml}$ & 0.40 & 0.53 & 0.62 & $1.88^{*}$ \\
\hline
\end{tabular}

\begin{tabular}{|l|cc|cc|}
\hline \multirow{2}{*}{ Variable } & \multicolumn{2}{|c|}{$1969: 01-1987: 12$} & \multicolumn{2}{c|}{$1988: 01-2006: 12$} \\
& $\lambda_{j}^{+}+\lambda_{j}^{-}-\theta_{j}$ & t-stat & $\lambda_{j}^{+}+\lambda_{j}^{-}-\theta_{j}$ & t-stat \\
\hline market & -1.01 & -1.01 & -1.15 & -1.16 \\
smb & 0.32 & 0.67 & 0.41 & 0.87 \\
$\mathrm{hml}$ & 1.45 & $3.31^{* * *}$ & 1.09 & $1.90^{*}$ \\
\hline
\end{tabular}

* significant (10-percent level)

*** significant (1-percent level)

This table depicts the results of the adjusted test for the four subperiods based on the block bootstrap. market is the risk premium of the market, smb that of the size and hml that of the book-to-market risk. $\lambda_{j}^{+}+\lambda_{j}^{-}-\theta_{j}$ are defined as presented in subsection 5.1.

caused by extreme returns, which distinctly increase the variance in short subperiods, but become less relevant for longer time periods.

All in all, our results show that the book-to-market beta is a priced risk factor, size beta is only priced for the entire period and market beta is not priced. Furthermore, we can subsume that the results from the adjusted test and the standard Fama-MacBeth test are qualitatively identical. Therefore, our findings place emphasis on the results of Freeman and Guermat (2006) but stand in sharp contrast to the results of Pettengill et al. (1995). Basing their test on the flawed hypothesis that beta is priced if there is a symmetric relationship betweeen the expected market excess return in down- and in up-markets Pettengill et al. (1995) find that market beta is a priced risk factor.

\subsection{Robustness}

In addition to the analysis based on portfolios sorted by the size and book-to-market factors, we conduct the same procedures for other portfolios not or only partly sorted by the risk factors contained in the Fama-French three-factor model in order to verify the results we obtained previously. First, we choose 10 portfolios sorted by momentum. 
Table 7: Fama-MacBeth test (1932:01-2006:12)

\begin{tabular}{|l|cll|cll|}
\hline \multirow{2}{*}{ Variable } & \multicolumn{4}{|c|}{25 momentum-size portfolios } & \multicolumn{3}{|c|}{10 momentum portfolios } \\
& $\lambda$ & t-stat & $\mathrm{R}^{2}$ & $\lambda$ & t-stat & $\mathrm{R}^{2}$ \\
\hline cons & 1.64 & $5.97^{* * *}$ & 0.71 & 1.79 & $4.26^{* * *}$ & 0.82 \\
market & -0.48 & -1.63 & & -0.65 & -1.37 & \\
smb & 0.40 & $3.07^{* * *}$ & & -0.45 & $-2.07^{* *}$ & \\
hml & -0.16 & -0.86 & & -0.36 & -1.18 & \\
\hline
\end{tabular}

** significant (5-percent level)

*** significant (1-percent level)

This table depicts the results for the Fama-French three-factor model illustrated by equation 2 when using 25 portfolios sorted by momentum and size as well as 10 portfolios sorted by momentum. cons denotes the constant term, market the risk premium of the market risk, smb that of the size and hml

that of the book-to-market risk. The coefficients are given as percentage points per month.

As it has been shown that momentum returns cannot be explained by the Fama-French three-factor model, this sorting appears to be an intuitive contrast to that with respect to size and book-to-market ratio and, thus, it is a useful robustness check of our existing test results. In contrast, other alternative risk factors proposed in the literature, such as long term reversal, can to a larger extent be explained by the three factors, which is why we prefer momentum. ${ }^{10}$ The portfolios are constructed monthly based on the stocks' previous 12 months composite return ${ }^{11}$. As it is desirable to have a larger number of data points in the cross-sectional regressions in order to reduce the standard errors of the estimates, we also choose to try and explain the returns of 25 portfolios sorted by momentum and size.

Table 7 depicts the results of the Fama-MacBeth test based on the 25 momentum-size portfolios as well as on 10 momentum portfolios. In the case of the 25 momentum-size portfolios size risk is priced whereas market risk and book-to-market risk are insignificant. On the one hand this is rather unsurprising since the portfolios are sorted with respect to size and, hence, we expect size to be a priced factor. On the other hand these results demonstrate that market and book-to-market risk do not make a contribution to the explanation of the portfolio returns. This is confirmed for the ten portfolios exclusively sorted with respect to momentum. In this case size risk is negatively priced, which means that the risk of buying stocks of small firms has a negative influence on the momentum

\footnotetext{
${ }^{10}$ The relevance of the reversal and the momentum factor is discussed in Cochrane (2005) p.445-448.

${ }^{11}$ Data are also taken from Kenneth French's homepage. For more details concerning the portfolio construction we refer to the explanations on his homepage.
} 
Table 8: Adjusted Test (1932:01-2006:12)

\begin{tabular}{|l|cc|cc|}
\hline Variable & \multicolumn{2}{|c|}{25 momentum-size portfolios } & \multicolumn{2}{l|}{10 momentum portfolios } \\
& $\lambda_{j}^{+}+\lambda_{j}^{-}-\theta_{j}$ & t-stat & $\lambda_{j}^{+}+\lambda_{j}^{-}-\theta_{j}$ & t-stat \\
\hline market & -0.55 & -0.74 & -1.16 & -1.27 \\
$\mathrm{smb}$ & 0.59 & $2.16^{* *}$ & -1.07 & $-2.40^{* * *}$ \\
$\mathrm{hml}$ & -0.32 & -0.68 & -0.43 & -0.73 \\
\hline
\end{tabular}

\footnotetext{
** significant (5-percent level)

$* * *$ significant (1-percent level)
}

This table depicts the results of the adjusted test for the entire period, using 25 portfolios sorted by momentum and size as well as 10 portfolios sorted by momentum. The estimation bases on the block bootstrap as explained in subsection 5.2. market denotes the risk premium of the market, smb that of the size and $\mathrm{hml}$ that of the book-to-market risk. $\lambda_{j}^{+}+\lambda_{j}^{-}-\theta_{j}$ are defined as presented in section 2 . The coefficients are given as percentage points per month.

returns. This observation may be caused by the fact that winner stocks, in particular portfolios seven to nine, are negatively correlated with the size factor. After a period of exceptional performance small firms still have significant opportunities to continue their fast growth while bigger ones are limited in their capacity to create further growth. Therefore bigger companies may be considered riskier and thus requiring a higher return due to their size.

As in the last subsection, the results of the adjusted test (table 8) affirm the FamaMacBeth test. Either tests produce similar results. The size factor is positively priced for the 25 momentum-size portfolios and negatively priced for the 10 momentum portfolios. The other two factors remain insignificant. For the sake of completeness we also present the results of the test of a conditional relationship between betas and return. As depicted in table 9 , all coefficients are highly significant such that we can conclude that there exists a strong relationship between Fama-French betas and return even for portfolios sorted with respect to momentum. ${ }^{12}$

\section{Summary and Conclusion}

Our results provide evidence that there exists a systematic relationship between the three Fama-French betas and return. Despite the inclusion of the size and book-to-market factors, we detect a systematic relationship between market beta and return. Furthermore, the two additional factors of the three-factor model amplify their explanatory power once

\footnotetext{
${ }^{12}$ The results for the subperiods are consistent with those results and are available on request.
} 
Table 9: Conditional Relation between Fama-French Betas and Returns (1932:01-2006:12)

\begin{tabular}{|l|cl|cl|}
\hline \multirow{2}{*}{ Variable } & \multicolumn{2}{|c|}{25 momentum-size portfolios } & 10 momentum portfolios \\
& $\lambda$ & t-stat & $\lambda$ & t-stat \\
\hline cons & 1.64 & $5.97^{* * *}$ & 1.79 & $4.26^{* * *}$ \\
market-up & 1.82 & $10.98^{* * *}$ & 1.29 & $4.16^{* * *}$ \\
market-down & -4.34 & $-18.40^{* * *}$ & -3.57 & $-7.82^{* * *}$ \\
smb-up & 2.36 & $70.21^{* * *}$ & 1.04 & $15.00^{* * *}$ \\
smb-down & -1.72 & $-32.92^{* * *}$ & -2.05 & $-22.23^{* * *}$ \\
hml-up & 0.65 & $10.15^{* * *}$ & 0.37 & $3.08^{* * *}$ \\
hml-down & -1.21 & $-16.15^{* * *}$ & -1.25 & $-9.60^{* * *}$ \\
\hline
\end{tabular}

This table depicts the results of the test for the conditional relationship between Fama-French betas and return using 25 portfolios sorted by momentum and size as well as 10 portfolios sorted by momentum. cons denotes the constant term, market up (down) the risk premium of the market given that the excess market return is positive (negative), smb up (down) that of the size given that the smb factor is positive (negative)and $\mathrm{hml} \mathrm{up} \mathrm{(down)} \mathrm{that} \mathrm{of} \mathrm{the} \mathrm{book-to-market} \mathrm{risk} \mathrm{given} \mathrm{that} \mathrm{the} \mathrm{hml} \mathrm{factor} \mathrm{is} \mathrm{positive}$ (negative). The coefficients are given as percentage points per month.

the conditional nature of the relation between beta and return is considered. Thus, the use of the conditional three-factor model betas estimated from historical price data by portfolio managers seems justified. However, if we go one step further and also test if beta risk is priced within the conditional approach, we discover that market beta is not priced whereas the other two factors are.

The Fama-MacBeth test has been challenged since many authors argue that the test too often rejects the hypothesis that beta risk is a priced factor. However, our study shows that the results of the adjusted test based on the conditional approach coincide with those from the standard Fama-MacBeth test procedure. Therefore, our findings suggest that the test procedure is not improved by the application of the conditional approach. To put it differently, our results confirm the standard Fama-MacBeth procedure. Because of the additional complexity of using the adjusted test the standard Fama-MacBeth test is favored.

Many previous studies have applied the conditional approach as proposed by Pettengill et al. (1995). The conditional approach takes into account that the use of realized returns leads to a negative risk-return relationship in down-markets. Thus, from the theoretical point of view the conditional approach is more appropriate. Even though, either previous 
studies test if beta risk is priced within the framework of the conditional approach but based on a wrong hypothesis (symmetry of the $\lambda$ coefficients) or they only test if there exists a conditional relationship between beta and return. In either cases the results of the test cannot be related to the results from the standard Fama-MacBeth procedure. In this paper we make these tests comparable by using the conditional approach to derive an adjusted test for priced beta and detect that the results are qualitatively identical using different data sets and checking four subperiods. Our results confirm those in Freeman and Guermat (2006). They show that either tests have a similar power in the special case of normally distributed returns.

We do not conclude that the conditional approach is irrelevant but we want to point out that the choice of the test procedure depends on the research question. Testing for priced beta risk does not make the conditional approach necessary. Nevertheless, if we only focus on testing for a systematic relationship between risk and return, then the conditional approach is suitable. 


\section{References}

Amihud, Y. and H. Mendelson (1986). Asset pricing and the bid-ask spread. Journal of Financial Economics 17, 223-249.

Amihud, Y. and H. Mendelson (1991). Liquidity and asset prices. Finanzmarkt und Portfolio Management 3, 235-240.

Babu, G. J. and K. Singh (1984). On one term edgeworth correction by efron's boostrap. Sankhya: The Indian Journal of Statistics 46(A), 219-232.

Banz, R. W. (1981). The relationship between return and market value of common stocks. Journal of Financial Economics 9, 3-18.

Black, F., M. Jensen, and M. Scholes (1972). Studies in the Theory of Capital Markets, Chapter The Capital asset pricing model: some empirical tests, pp. 79-121. Praeger, New York.

Cochrane, J. (2005). Asset Pricing (revised ed.). Princeton University Press.

Efron, B. (1979). Bootstrap methods: Another look at the jackknife. Annals of Statistics $7,1.26$.

Elsas, R., M. El-Shaer, and E. Theissen (2003). Beta and returns revisited: Evidence from the german stock market. International Financial Markets, Institutions 69 Money 13, $1-18$.

Fama, E. F. and K. R. French (1992). The cross-section of expected stock returns. Journal of Finance $47(2), 427-465$.

Fama, E. F. and K. R. French (1993). Common risk factors in the returns on stocks and bonds. Journal of Financial Economics 33, 3-56.

Fama, E. F. and K. R. French (1996). Multifactor explanations of asset pricing anomalies. Journal of Finance 51(1), 55-84.

Fama, E. F. and J. D. MacBeth (1973). Risk, return, and equilibrium: Empirical tests. Journal of Political Economy 81(3), 607-636.

Ferson, W. E. and C. R. Harvey (1991). The variation of economic risk premiums. Journal of Political Economy 99, 285-315. 
Ferson, W. E. and C. R. Harvey (1993). The risk and predicitability of international equity returns. Review of Financial Studies 6(3), 527-566.

Fletcher, J. (2000). On the conditional relationship between beta and return in international stock returns. International Review of Financial Analysis 9, 235-245.

Fraser, P., F. Hamelink, M. Hoesli, and B. MacGregor (2004). Time-varying beta and the cross-sectional return-risk relation: evidence from the uk. The European Journal of Finance 10, 255-276.

Freeman, M. C. and C. Guermat (2006). The conditional relationship between beta and returns: A reassessment. Journal of Business Finance \& Accounting 33(7-8), 12131239.

Groenewold, N. and P. Fraser (1997). Share prices and macroeconomic factors. Journal of Business Finance 8 Accounting 24, 1367-1383.

Harvey, C. R. (1989). Time-varying conditional covariances in tests of asset pricing models. Journal of Financial Economics 24, 289-317.

Huang, P. and C. J. Hueng (forthcoming). Conditional risk-return relationship in a timevarying beta model. Quantitative Finance.

Hung, D. C.-H., M. Shackleton, and X. Xu (2004). Capm, higher co-moment and factor models of uk stock returns. Journal of Business Finance $\&$ Accounting 31(1-2), 87-112.

Jagannathan, R. and Z. Wang (1996). The conditional capm and the cross-section of expected returns. Journal of Finance 51(1).

Künsch, H. R. (1989). The jackknife and the bootstrap for general stationary observations. The Annals of Statistics 17, 1217-1261.

Lahiri, S. N. (1999). Theoretical comparison of block bootstrap methods. The Annals of Statistics 27, 386-404.

Lettau, M. and S. Ludvigson (2001). Resurrecting the (c)capm: A cross-sectional test when risk premia are time-varying. Journal of Political Economy 109(6), 1238-1287.

Lintner, J. (1965). The valuation of risk assets and the selection of risky investments in stock portfolios and capital budgets. Review of Economics and Statistics 47(13-37).

Mossin, J. (1966). Equilibrium in a capital asset market. Econometrica 34(4), 768-783. 
Pettengill, G. N., S. Sundaram, and I. Mathur (1995). The conditional relation between beta and return. Journal of Financial and Quantitative Analysis 30(1), 101-116.

Reinganum, M. R. (1981). A new empirical perspective on the capm. Journal of Financial and Quantitative Analysis 16(4), 439-462.

Roll, R. (1977). A critique of the asset pricing theory's tests: Part i: On past and potential testability of the theory. Journal of Financial Economics 4, 129-176.

Shanken, J. (1992). On the estimation of beta-pricing models. The Review of Financial Studies 5(1), 1-33.

Shanken, J. and M. Weinstein (2006). Economic forces and the stock market revisited. Journal of Empirical Finance 13, 129-144.

Sharpe, W. F. (1964). Capital asset prices: A theory of market equilibrium under conditions of risk. Journal of Finance 19(3), 425-442.

Vassalou, M. and Y. Xing (2004). Default risk and equity returns. Journal of Finance 59, 831.868 .

White, H. (1999). Asymptotic Theory for Econometricias. San Diego: Academic Press. 